\title{
Coronary Subclavian Steal Syndrome
}

Rady Ho, MD

Thomas Jefferson University Hospital, rady.ho@jefferson.edu

Jonathan A. Dunn, MD

Thomas Jefferson University Hospitals, Jonathan.Dunn@jefferson.edu

Follow this and additional works at: https://jdc.jefferson.edu/tmf

Part of the Cardiology Commons, and the Internal Medicine Commons

Let us know how access to this document benefits you

\section{Recommended Citation}

Ho, MD, Rady and Dunn, MD, Jonathan A. (2016) "Coronary Subclavian Steal Syndrome," The Medicine Forum: Vol. 17 , Article 5.

DOI: https://doi.org/10.29046/TMF.017.1.006

Available at: https://jdc.jefferson.edu/tmf/vol17/iss1/5

This Article is brought to you for free and open access by the Jefferson Digital Commons. The Jefferson Digital Commons is a service of Thomas Jefferson University's Center for Teaching and Learning (CTL). The Commons is a showcase for Jefferson books and journals, peer-reviewed scholarly publications, unique historical collections from the University archives, and teaching tools. The Jefferson Digital Commons allows researchers and interested readers anywhere in the world to learn about and keep up to date with Jefferson scholarship. This article has been accepted for inclusion in The Medicine Forum by an authorized administrator of the Jefferson Digital Commons. For more information, please contact: JeffersonDigitalCommons@jefferson.edu. 


\title{
Coronary Subclavian Steal Syndrome
}

\author{
Rady Ho, MD, Jonathan Dunn, MD
}

\section{INTRODUCTION}

Coronary subclavian steal (CSS) syndrome is a rare complication of coronary artery bypass graft surgery (CABG) involving the left internal mammary artery (LIMA) graft to the left anterior descending (LAD) artery. It results from stenosis of the left subclavian artery proximal to the LIMA, which compromises myocardial blood flow. The incidence of CSS syndrome is between 0.1-3.4\% in the United States. ${ }^{1}$ Most cases occur as a result of long-standing subclavian stenosis due to progres-sion of the stenosis following CABG. We report a case of CSS syndrome, which presented as a non-ST elevation myocardial infarction (NSTEMI).

\section{CASE PRESENTATION}

A 76 year-old male with a past medical history of hypertension, coronary artery disease, myocardial infarction in 2007, left carotid artery stenosis, stroke in 2009, and end-stage renal disease on hemodialysis presented to the emergency department with two weeks of exertional chest pain, worsening fatigue and shortness of breath. On the morning of presentation, he developed chest pain at rest and came to the emergency department. This patient was treated for myocardial infarction with a three-vessel CABG in 2007: he had a LIMA graft to the $L A D$, and saphenous vein grafts to the obtuse marginal artery, and posterior descending artery.

On physical examination, he was found to be tachypneic, tachycardic and hypoxic. Electrocardiogram revealed ST segment depressions in the anterolateral leads and his troponins were ele-vated at $2.81 \mathrm{ng} / \mathrm{dL}$. The patient was admitted to the hospital for NSTEMI and was started on aspirin, atorvastatin, metoprolol and a heparin infusion.

An echocardiogram revealed akinesis of the apex, anterior septum, mid to distal inferior septum, mid to distal anterolateral wall, distal inferior wall and mid to distal inferolateral wall, all of which were not present on an echocardiogram performed the previous month. A subsequent cardiac catheterization revealed a patent LIMA, however it showed significant stenosis of the left subcla-vian artery proximal to the origin of the LIMA. Although all the findings of the echocardiogram could not be explained by the catheterization findings, the decision was made to intervene. Angioplasty and stenting of the left subclavian artery was performed, and this resulted in complete resolution of his symptoms. The ST segment normalized. Repeat echocardiogram revealed mild to moderation left ventricular function with ejection fraction of $40 \%$.

\section{DISCUSSION}

This case highlights the difficulties that can arise in the treatment of CSS syndrome, particularly when it is unclear whether the pattern of ischemia is caused by the stenosis of the subclavian artery. In this case, the defects on echocardiogram pointed to flow limitation in the territory of the left main coronary artery. However, angiography revealed a patent left main. There was stenosis of the left subclavian artery leading to flow limitation to the distal LAD. Based on these findings, it was unclear whether the patient's symptoms were caused by CSS syndrome.

Modalities of treatment of CSS syndrome include medical therapy alone, percutaneous intervention, and surgical revascularization. The success rate for angioplasty and stent placement to the subclavian artery is $80-100 \%$. 2,3 Complication rates are reported to be between 3-6\%, with the major complication being distal embolization. The rate of instent restenosis is reported to be between 3-6\% at 20 months. ${ }^{2}$ In contrast, surgical options such as carotid to subclavian bypass have morbidity rates between $15-33 \%$, and mortality between 5-8\%. Currently, there are no randomized clinical trials comparing the efficacy of one strategy versus another. However, most agree that in the setting of symptoms, surgical or endovascular therapy is indicated.

In a retrospective study, Schillinger et al compared patients treated with endovascular intervention to those treated with medical therapy alone. The study found that patients with ischemic symptoms were more likely to be intervened on, and asymptomatic patients were likely to be treated medically. However, there was no significant difference in the number of patients with symptomatic disease at the time of follow-up between both groups. They concluded that in the absence of symptoms, patients should not be intervened on based on hemodynamic findings alone.

For our patient, the decision was made to intervene using percutaneous transluminal angioplasty and stenting based on the presence of symptoms and stenosis of the subclavian artery. He did well post-procedure and reported remission of his symptoms. Ischemic findings on his ECG resolved and repeat echocardiogram showed improvement of the left ventricular function. 


\section{KEY POINTS}

- Coronary subclavian steal (CSS) syndrome is a rare complication of coronary artery bypass graft (CABG) involving the left internal mammary artery (LIMA) graft to the left anterior descending (LAD) artery.

- Though CSS is rare but not uncommon; therefore, it should be included in the differential diagnosis in patients with CABG presenting with chest pain.

- Modalities of treatment include medical therapy alone, percutaneous intervention, and surgical revascularization.

\section{REFERENCES}

1. Takach TJ, Reul GJ, Duncan JM, Krajcer Z, Livesay JJ, Gregoric ID, et al. Concomitant brachio-cephalica and coronary artery disease: outcome and decision analysis. Ann Thorac Surg. 2005; 80(2):564-9

2. Hadjipetrou P, Cox S, Piemonte T, et al: Percutaneous revascularization of atherosclerotic ob-struction of aortic arch vessels. J Am Coll Cardiol 33:1238-1245, 1999

3. Jain SP, Zhang Sy, Kosla S, et al: Subclavian and innominate artery stenting: Acute and long-term results. J Am Coll Cardiol 31:63A, 1998

4. al-Mobarak N, Liu MW, Dean LS, et al: Immediate and late outcomes of subbclavian artery stenting. Catheter Cardiovasc Interv 46:169-172, 1999

5. Bogey WM, Demasi RJ, Tripp MD, Vithalani R, Johnsrude IS, Powell SC, Percutaneous transluminal angioplasty for subclavian artery stenosis. Am Surg 1994; 60: 103-106

6. Schillinger M, Haumer M, Schillinger S, Mlekusch W, Ahmedi R. Outcome of conservative versus interventional treatment of subclavian artery stenosis. J Endovasc Ther 2002; 9: 139-146

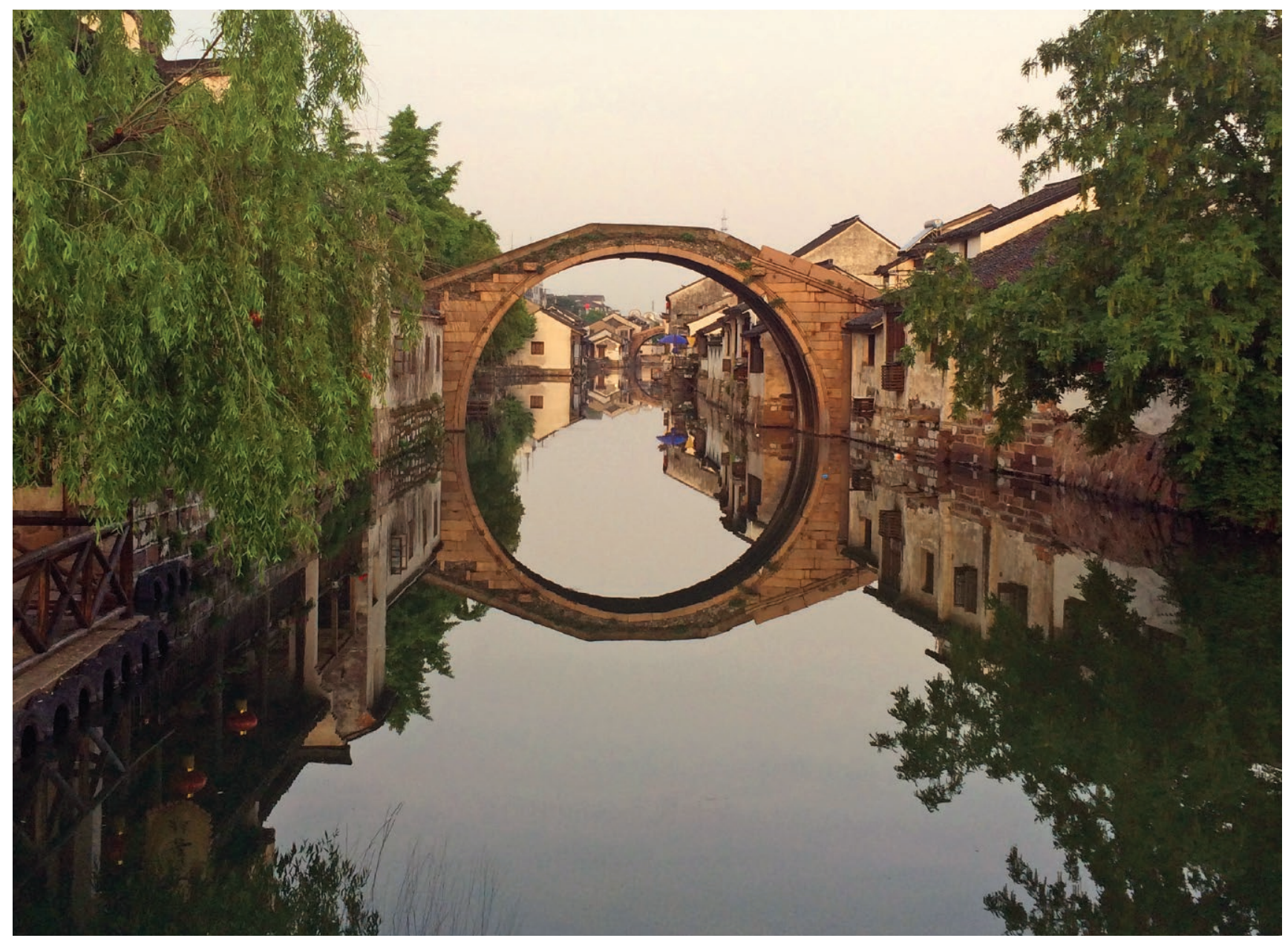

Shuwei Wang, MD 